\title{
Rendimento e qualidade de melancia cultivada sob proteção de agrotêxtil combinado com mulching plástico ${ }^{1}$
}

\author{
Mara S. M. Dantas' ${ }^{2}$, Leilson C. Grangeiro ${ }^{3}$, José F. de Medeiros ${ }^{3}$, \\ Claudia A. $\mathrm{Cruz}^{4} \&$ Ana P. A. da Cunha ${ }^{3}$
}

\begin{abstract}
RESUMO
A cobertura do solo é uma prática agrícola que visa controlar principalmente as plantas daninhas enquanto o agrotêxtil impede o ataque de pragas. O objetivo deste trabalho foi avaliar o rendimento e a qualidade dos frutos da melancia cultivada sob proteção de agrotêxtil combinado com mulching plástico. O experimento foi realizado na empresa WG Fruticultura, Baraúna, RN. Utilizou-se o delineamento em blocos ao acaso em esquema fatorial $3 \times 3+1$ com quatro repetições e 36 plantas por parcela sendo o primeiro fator composto por cores de mulching plástico (preto, prata e branco) e o segundo fator por agrotêxtil com diferentes tempos de uso (agrotêxtil de primeiro e terceiro cultivos e sem agrotêxtil) e testemunha absoluta (sem mulching e sem agrotêxtil). Analisaram-se as variáveis de produção (produtividade de frutos comerciais, produtividade não comercial e produtividade total) e a qualidade dos frutos (sólidos solúveis - SS, acidez titulável - AT, relação SS/AT). O uso do mulching e da proteção das plantas com agrotêxtil, independente do tempo de uso, proporcionou maior rendimento de frutos de melancia em relação ao solo descoberto e sem a proteção com agrotêxtil. A qualidade dos frutos não foi afetada pelo uso do mulching e do agrotêxtil.
\end{abstract}

Palavras-chave: Citrullus lanatus L., cobertura do solo, cultivo protegido, produção

\section{Yield and quality of watermelon grown under nonwoven textile protection combined with plastic mulching}

\begin{abstract}
The ground cover is an agricultural practice that is designed mainly to control weeds, while the nonwoven prevents the attack of pests. The objective of this study was to evaluate the yield and fruit quality of watermelon grown under nonwoven textile protection combined with plastic mulching. The experiment was conducted at the WG Fruits Company, Baraúna, RN. A randomized block design was used in a factorial $3 \times 3+1$ with four replications, and 36 plants per plot, with the first factor of color of plastic used in mulching (black, silver and white) and the second factor nonwoven textile with different times of use (first and third crop nonwoven under textile and without nonwoven) and an absolute control (no mulching and without nonwoven). The production variables evaluated were: yield (commercial, noncommercial, and total fruit yield), and fruit quality (soluble solids - SS, titratable acidity - TA and SS/TA). The use of mulching and protection of plants with nonwoven textile provided a higher yield of watermelon fruits in relation to bare soil with and without nonwoven textile protection. Fruit quality was not affected by the use of mulching and nonwoven.
\end{abstract}

Key words: Citrullus lanatus L., soil cover, protected cultivation, production

\footnotetext{
Parte da Dissertação de Mestrado do primeiro autor apresentada ao Programa de Pós-Graduação em Fitotecnia UFERSA

${ }^{2}$ UFRPE, R. Dom Manoel de Medeiros, s/n, Dois Irmãos, CEP 52171-900, Recife, PE. Fone: (81) 3320-6279. E-mail: mara suy@hotmail.com

3 UFERSA, BR 110, Km 47, 11, CEP 59625-900, Mossoró, RN. Fone: (84) 3317 8547. E-mail: leilson@ufersa.edu.br; jfmedeir@ufersa.edu.br; apalves cunha@hotmail.com

${ }^{4}$ UNESP, Via de Acesso Prof. Paulo Donato Castellane, s/n, CEP 14884-900 - Jaboticabal, SP. Fone: (16) 3209-2600. E-mail: mariahclaudia@hotmail.com
} 


\section{INTRODUÇÃO}

A melancia (Citrullus lanatus L.) se destaca no cenário nacional como a quarta hortaliça de maior importância, com uma área cultivada de 94 mil hectares e uma produção de aproximadamente dois milhões de toneladas de frutos. Os maiores produtores nacionais são os estados do Rio Grande do Sul, Bahia, Goiás, São Paulo, Paraná, Pará, Pernambuco e Rio Grande do Norte (IBGE, 2011).

Nos estados do Rio Grande do Norte e Ceará o cultivo da melancia tem despertado o interesse dos produtores pois há uma demanda crescente no mercado internacional por frutos sem sementes e do tipo Personal size. No entanto, por pertencer à mesma família do melão seu cultivo na região não é uma tarefa fácil visto que é atacado por pragas em praticamente todas as suas fases fenológicas. Este fato faz com que sejam utilizadas grandes quantidades de defensivos agrícolas para o controle de pragas e doenças. Estima-se que sejam feitas até 25 aplicações de agrotóxicos durante um ciclo da melancia o que corresponde a uma aplicação a cada dois dias quando não se utiliza o agrotêxtil (Dantas, 2010).

Uma das alternativas encontradas pelos produtores da região é a utilização do agrotêxtil combinado com o mulching plástico. Essas técnicas podem aperfeiçoar o sistema de produção e melhorar a qualidade pós-colheita dos frutos em virtude de reduzir a oscilação da temperatura e da evaporação da água na superfície do solo diminuir a perda de adubos e corretivos por lixiviação, além de evitar a compactação, a erosão do solo e o contato direto dos frutos com o mesmo (Câmara et al., 2007). O agrotêxtil é uma técnica de manejo que visa, sobretudo, controlar a incidência de pragas e, em consequência, reduz o número pulverizações por ciclo já que as plantas permanecem protegidas por aproximadamente 21 dias, momento em que o florescimento se inicia e o agrotêxtil é então retirado reduzindo em média 10 pulverizações (Dantas, 2010).

O agrotêxtil, também conhecido como "não-tecido" de polipropileno, é um material usado como cobertura para proteção da planta e do solo. É bastante leve, poroso, permitindo a passagem de água e gases, bem como $85 \%$ da radiação que chega à sua superfície confeccionado a partir de longos filamentos de polipropileno que são colocados em camadas e moldadas entre si por temperaturas apropriadas, constituindo-se em um material leve e de resistência suficiente para ser utilizado na agricultura, na gramatura de 16 a $25 \mathrm{~g} \mathrm{~m}^{-2}$ (ABINT, 2000).

$\mathrm{O}$ agrotêxtil mais utilizado na região do Agropolo AssuMossoró-Baraúna/RN é o de coloração branca e gramatura de $15 \mathrm{~g} \mathrm{~m}^{-2}$, sendo reutilizados por até três ciclos consecutivos (Dantas, 2010). Medeiros et al. (2007) observaram, estudando o uso do agrotêxtil na cultura do melão na região de Mossoró, $\mathrm{RN}$, aumento do número de frutos comercializáveis e totais e o atribuíram ao fato das plantas terem permanecido livres de pragas durante parte do ciclo proporcionando maior acúmulo de massa foliar e, em contrapartida, aumento da eficiência fotossintética.

O mulching plástico vem sendo utilizado com diferentes objetivos na agricultura e seus efeitos são variáveis em função da cor de mulching utilizado. As principais cores de mulching plásticos usados como coberturas do solo, são: os transparentes, brancos, pretos, pratas e opacos. A utilização do mulching plástico tem potencial para a redução das perdas de água por evaporação, o que pode reduzir o consumo de água de 5 a 30\% pela cultura (Allen et al., 1998). O uso de cobertura plástica pode reduzir danos e doenças nos frutos haja vista que seu contato com o solo diminuiu implicando na sua qualidade e na sua apresentação. Além disto, a evaporação da superfície do solo também diminui, contribuindo significativamente para a redução da evapotranspiração das culturas (Silva, 2002).Sendo responsável, ainda, por aumentar a produtividade e a qualidade de frutos em diversas culturas,Jiménezet al.(2001), Câmara et al. (2007), Moreno et al. (2005). Diversos pesquisadores vêm estudando o efeito do mulching plástico em várias culturas e sob vários aspectos Jiménez et al. (2001; 2004; 2005; 2008), Silva et al. (2005), Medeiros et al. (2007), Câmara et al. (2007), Liu et al. (2009) e Dantas et al. (2011).

Tendo em vista que a cor do mulching plástico utilizado na cobertura do solo promove mudanças no comportamento da cultura no campo e no preço do mulching, torna-se necessária a realização de pesquisas para determinar a cor que proporcionará maiores rendimentos e qualidade dos frutos. Quanto ao agrotêxtil, na literatura são escassas ou não existem pesquisas sobre reúso do agrotêxtil sendo encontrados apenas estudos envolvendo cultivo na presença ou ausência deste material, tornando-se imprescindível, portanto, a realização de estudos que confirmem a viabilidade e a eficiência do reaproveitamento do agrotêxtil após sua reutilização por vários ciclos, no potencial produtivo, qualidade dos frutos $\mathrm{e}$ no controle das pragas.

Com base neste contexto objetivou-se, com este trabalho, avaliar o rendimento e a qualidade dos frutos da melancia cultivada sob proteção agrotêxtil com diferentes tempos de uso combinado com mulching plástico de diversas cores.

\section{Material e Métodos}

O experimento foi conduzido na Fazenda Sumidouro, município de Baraúna, RN, pertencente à empresa WG Fruticultura cujas coordenadas geográficas são: $5^{\circ} 04^{\prime} 44^{\prime \prime} \mathrm{S}$, $37^{\circ} 37^{\prime} 26^{\prime}$ W, no período de setembro a novembro de 2009, em solo classificado como Cambissolo Háplico (EMBRAPA, 1999).As análises químicas do solo da área experimental foram realizadas no Laboratório de Química e Fertilidade de Solos pertencente à UFERSA, de acordo com os metodos descritos por (Silva, 2009), apresentados na (Tabela 1).

Tabela 1. Análises químicas do solo da área experimental

\begin{tabular}{|c|c|c|c|c|c|c|c|}
\hline \multirow{3}{*}{$\begin{array}{c}\text { Prof. } \\
\text { (cm) } \\
0-20 \mathrm{~cm}\end{array}$} & \multirow{2}{*}{$\begin{array}{c}\mathrm{pH} \\
\left(\mathrm{H}_{2} \mathrm{O}\right)\end{array}$} & $\overline{\mathbf{P}}$ & $\overline{\mathbf{K}^{+}}$ & $\mathrm{Ca}^{2+}$ & $\mathrm{Mg}^{2+}$ & $\mathrm{Na}^{+}$ & $\overline{\mathbf{A l}^{3+}}$ \\
\hline & & \multicolumn{2}{|c|}{$\mathrm{mg} \mathrm{dm}^{-3}$} & \multicolumn{4}{|c|}{$\mathrm{cmol}_{\mathrm{c}} \mathrm{dm}^{-3}$} \\
\hline & 7,5 & 47,8 & 288,7 & 60,3 & 1,8 & 6,3 & 0,00 \\
\hline
\end{tabular}

O delineamento experimental utilizado foi em blocos ao acaso em esquema fatorial $3 \times 3+1$ com quatro repetições e 36 plantas por parcela, sendo o primeiro fator composto 
por três cores mulching plástico dupla face (preto-preto, branco-preto e prata-preto) e o segundo fator agrotêxtil com diferentes tempos de uso (agrotêxtil novo ou de primeiro cultivo e agrotêxtil de terceiro cultivo, ou seja, o agrotêxtil que estava sendo utilizado pela terceira vez) e a testemunha absoluta (sem mulching e sem agrotêxtil) cujos tratamentos estão apresentados na (Tabela 2).

\section{Tabela 2. Descrição dos tratamentos}

\begin{tabular}{cl}
\hline Tratamentos & \multicolumn{1}{c}{ Descrição } \\
T1 & Mulching plástico prata-preto com agrotêxtil de $1^{\circ}$ cultivo \\
T2 & Mulching plástico prata-preto com agrotêxtil de $3^{\circ}$ cultivo \\
T3 & Mulching plástico prata-preto, sem agrotêxtil \\
T4 & Mulching plástico branco-preto com agrotêxtil de $1^{\circ}$ cultivo \\
T5 & Mulching plástico branco-preto com agrotêxtil de $3^{\circ}$ cultivo \\
T6 & Mulching plástico branco-preto, sem cobertura com agrotêxtil \\
T7 & Mulching plástico preto-preto com agrotêxtil de $3^{\circ}$ cultivo \\
T8 & Mulching plástico preto-preto com agrotêxtil de $3^{\circ}$ cultivo \\
T9 & Mulching plástico preto-preto, sem cobertura com agrotêxtil \\
T10 & Sem mulching e sem agrotêxtil \\
\hline
\end{tabular}

Cada parcela experimental foi composta por fileiras de 6,0 $\mathrm{m}$ de comprimento e espaçadas $2,0 \mathrm{~m}$, totalizando uma área experimental de $960 \mathrm{~m}^{2}$. A área útil por parcela foi de $10,0 \mathrm{~m}^{2}$, correspondendo às 10 plantas da fileira central desprezando-se as duas plantas das extremidades, no total de 36 plantas por parcela.

O preparo do solo constou de aração e gradagem seguida do sulcamento em linhas espaçadas $2,0 \mathrm{~m}$ e com profundidade de $0,30 \mathrm{~m}$. A adubação foi realizada com base na análise do solo sendo colocados em fundação $10 \mathrm{t} \mathrm{ha}^{-1}$ do adubo orgânico polifertil e $500 \mathrm{~kg} \mathrm{ha}^{-1}$ da formulação comercial 6-24-12. Os mulching plásticos foram colocados sobre o solo e posteriormente perfurados no espaçamento de $0,50 \mathrm{~m}$.

Utilizou-se a melancia Quetzale, uma variedade precoce com colheita aos 70 dias, peso variando de 2,5 a $6,0 \mathrm{~kg}$, casca de cor verde com estrias escuras e finas, polpa vermelha e com poucas sementes (Almeida et al., 2010). A semeadura foi realizada em bandejas de poliestireno expandido para 128 mudas, preenchidas com substrato comercial plantmax; as mudas foram transplantadas aos 12 dias após a emergência utilizando-se o espaçamento de 2,0 x $0,5 \mathrm{~m}$. Após o transplantio nos tratamentos que receberam a proteção com agrotêxtil, as plantas foram cobertas com o agrotêxtil formando uma espécie de túnel, no qual permaneceram cobertas pelo tempo de 21 dias (início de florescimento das plantas de melancia). A irrigação foi realizada por gotejamento, com emissores espaçados $0,5 \mathrm{~m}$ e vazão de $1,6 \mathrm{~L} \mathrm{~h}^{-1}$ enquanto as lâminas foram determinadas com base nos dados de evapotranspiração (Allen et al., 1998) sendo aplicada, durante todo o ciclo, uma lâmina $313 \mathrm{~mm}$. A adubação de cobertura foi realizada via água de irrigação utilizando-se $165 \mathrm{~kg} \mathrm{ha}^{-1}$ de $\mathrm{N}, 82,5 \mathrm{~kg} \mathrm{ha}^{-1}$ de $\mathrm{P}_{2} \mathrm{O}_{5}$ e 189 $\mathrm{kg} \mathrm{ha}^{-1}$ de $\mathrm{K}_{2} \mathrm{O}$, nas formas de ureia, nitrato de cálcio, ácido nítrico, MAP, ácido fosfórico e cloreto de potássio. Como fonte de micronutrientes foi aplicado, aos $38^{\circ}$ dias após a semeadura, $0,6 \mathrm{~kg} \mathrm{ha}^{-1}$ da formulação comercial contendo $5,0 \%$ de $\mathrm{B}, 1,5$ de $\mathrm{Cu}, 4 \%$ de $\mathrm{Fe}, 5,4$ de $\mathrm{Mg}, 4,0 \%$ de $\mathrm{Mn}$, $0,1 \%$ de Mo, $3,0 \%$ de $\mathrm{S}$ e $1,5 \%$ de $\mathrm{Zn}$. A colheita dos frutos foi iniciada aos 56 dias após transplantio sendo realizadas duas colheitas com intervalos de cinco dias.
As características avaliadas referentes à produção e à qualidade, foram: número médio de frutos planta $^{-1}$, massa média de frutos comerciais $(\mathrm{kg})$, produtividade de frutos comerciais $\left(\mathrm{t} \mathrm{ha}^{-1}\right)$, produtividade de frutos não comerciais $\left(\mathrm{t} \mathrm{ha}^{-1}\right)$, produtividade total de frutos $\left(\mathrm{tha}^{-1}\right)$, sólidos solúveis ( ${ }^{\circ}$ Brix), acidez titulável e Relação SS/AT.

Os dados foram submetidos a análises de variância e as médias comparadas pelo teste de Duncan, a nível de 0,05 de probabilidade utilizando-se o programa SISVAR.

\section{Resultados E Discussão}

Não houve interação significativa entre os fatores mulching plástico e agrotêxtil para nenhuma das características avaliadas. Observou-se efeito significativo para o fator mulching e para o fator agrotêxtil, nas variáveis massa média de frutos (MMF), produtividade não comercial (PNC), produtividade comercial (PC) e produtividade total (PT) porém não se constatou efeito significativo para número de frutos por planta (NFP) (Tabela 3 ).

Tabela 3. Valores médios para número de frutos planta $^{-1}$ (NFP), massa média de frutos (MMF), produtividade de frutos não comercial (PNC), comercial (PC) e total (PT) de melancia, cv. Quetzale

\begin{tabular}{|c|c|c|c|c|c|}
\hline \multirow{3}{*}{ Fatores } & \multicolumn{5}{|c|}{ Variáveis avaliadas } \\
\hline & \multirow{2}{*}{$\begin{array}{c}\text { MMF } \\
(\mathrm{kg})\end{array}$} & PC & PT & PNC & \multirow{2}{*}{$\begin{array}{l}\text { NFP } \\
\text { (und) }\end{array}$} \\
\hline & & \multicolumn{3}{|c|}{$\left(\mathrm{t} \mathrm{ha}^{-1}\right)$} & \\
\hline \multicolumn{6}{|l|}{ Cor de mulching } \\
\hline Prata & $3,70 \mathrm{~A}$ & $89,39 \mathrm{~A}$ & $90,75 \mathrm{~A}$ & $1,36 \mathrm{~B}$ & $1,44 \mathrm{~A}$ \\
\hline Branco & $3,41 \mathrm{~A}$ & $82,26 \mathrm{~A}$ & $85,07 \mathrm{~A}$ & $2,82 \mathrm{~A}$ & $1,58 \mathrm{~A}$ \\
\hline Preto & $3,54 \mathrm{~A}$ & $87,68 \mathrm{~A}$ & $88,22 \mathrm{~A}$ & $0,54 \mathrm{~B}$ & $1,34 \mathrm{~A}$ \\
\hline Testemunha & $2,80 \mathrm{~B}$ & $57,54 \mathrm{~B}$ & $60,89 \mathrm{~B}$ & $3,35 \mathrm{~A}$ & $1,30 \mathrm{~A}$ \\
\hline $\mathrm{F}$ & $3,61^{*}$ & $14,51^{\star \star}$ & $14,3^{\star \star}$ & $3,14^{*}$ & $0,49^{\text {ns }}$ \\
\hline CV (\%) & 12,34 & 9,78 & 8,94 & 72,20 & 25,25 \\
\hline \multicolumn{6}{|c|}{ Tempo de uso do agrotêxtil } \\
\hline $1^{0}$ cultivo & $3,47 \mathrm{~A}$ & $86,33 \mathrm{~A}$ & $87,52 \mathrm{~A}$ & $1,19 \mathrm{AB}$ & $1,55 \mathrm{~A}$ \\
\hline $3^{0}$ cultivo & $3,64 \mathrm{~A}$ & $87,27 \mathrm{~A}$ & $90,32 \mathrm{~A}$ & $3,05 \mathrm{~A}$ & $1,39 \mathrm{~A}$ \\
\hline Sem agrotêxtil & $3,52 \mathrm{~A}$ & $85,72 \mathrm{~A}$ & $86,21 \mathrm{~A}$ & $0,49 \mathrm{~B}$ & $1,41 \mathrm{~A}$ \\
\hline Testemunha & $2,79 \mathrm{~B}$ & $57,54 \mathrm{~B}$ & $60,89 \mathrm{~B}$ & $3,35 \mathrm{~A}$ & $1,30 \mathrm{~A}$ \\
\hline $\mathrm{F}$ & $3,60^{*}$ & $29,01^{* \star}$ & $23,94^{\star \star}$ & $4,55^{*}$ & $0,36^{\text {ns }}$ \\
\hline CV $(\%)$ & 12,04 & 6,78 & 6,88 & 64,90 & 24,53 \\
\hline
\end{tabular}

Médias seguidas da mesma letra maiúscula, na coluna, não diferem entre si pelo teste de Duncan a 0,05 de probabilidade; * significativos a $0,05(p>0,05) ;{ }^{* \star}$ significativos a 0,01 ( $>0,01) ;$; não significativo

Para o fator mulching observou-se diferença significativa ( $\mathrm{p}$ $<0,05)$ pelo teste de Ducan para as variáveis MMF, PC e PT, entre os tratamentos com mulching em relação à testemunha (Tabela 3). Os menores valores de MMF, PC e PT foram observados no tratamento testemunha enquanto os maiores valores foram constatados nos tratamentos com mulching plástico não sendo observada diferença entre as cores de mulching. Segundo Streck et al. (1994) as coberturas opacas (preto, branco e coloridas de plásticos, papel, petróleo, betume e palha) diminuem o fluxo de calor no solo e a amplitude diária da temperatura da terra. Coberturas transparentes e translúcidas promovem aumento da radiação líquida na superfície do solo, aumento do fluxo de calor do solo e, como consequência, a temperatura mínima e a máxima do solo também são aumentadas; deste modo, é provável que o aumento nos componentes de produção das plantas observados neste trabalho para os tratamentos com 
mulching plástico, possa ser atribuído à redução da energia solar e da temperatura do solo já que esses materiais possuem um albedo maior em relação ao solo descoberto. Segundo Horton et al. (1996) a palha usada na superfície do solo tem albedo maior e menor condutividade térmica em relação ao solo nu e, consequentemente, reduz a energia solar que atinge o solo e reduz também a magnitude da temperatura durante condições quentes. Rendimentos mais elevados com a utilização do mulching foram atribuídos sobretudo ao aumento da água no solo em condições áridas e semiáridas (Huang et al., 2005; Zhang et al., 2009).

Em relação à variável PNC observou-se melhor resultado com os mulchings de cores preto e prata, os quais não diferiram significativamente. Esses tratamentos apresentaram menor quantidade de frutos refugados refletindo diretamente no aumento da produção total enquanto o tratamento com mulching de cor branca e a testemunha apresentaram resultados semelhantes para esta variável.

Analisando os valores médios obtidos com a utilização do mulching em relação à testemunha, verificou-se um aumento de $50,23 \%$ na produção comercial apenas com a utilização do mulching plástico. Em relação à MMF, a utilização do mulching proporcionou um aumento médio $26,78 \%$ quando comparado com a testemunha (Tabela 3 ). O mulching plástico tem sido amplamente utilizado na agricultura pois afeta significativamente o microclima do solo (temperatura e teor de água) Ghosh et al. (2006) afirmam que a cobertura do solo promove, independente da cor, um aumento nos componentes de produção da cultura em relação ao solo descoberto e pode ser atribuído, provavelmente, à melhoria da retenção da água no solo e das condições térmicas em relação ao solo descoberto. Negreiros et al. (2005) e Medeiros et al.(2006) obtiveram respostas positivas na cultura do meloeiro de forma que os maiores valores de produtividade foram obtidos no cultivo com mulching plástico; do mesmo modo, Dantas et al.(2011) constataram, estudando a utilização dos filmes plásticos, que o uso do mulching plástico proporcionou um aumento médio de $20 \%$ no peso médio dos frutos embora com os filmes plásticos preto e branco sendo superiores ao prata; no entanto, Araújo et al. (2003) e Miranda et al. (2003) não obtiveram respostas significativas demonstrando, assim, que a resposta das culturas à cobertura do solo é variável em função da cultura estudada e das condições ambientais de cultivo.

A provável redução da perda de água do solo em virtude da menor evaporação e regulação da temperatura do solo em função da utilização dos mulchings plásticos (Ramakrishna et al., 2006) durante o crescimento da cultura, possivelmente estimulou os processos fisiológicos das plantas as quais expressaram seu potencial produtivo. A manutenção da umidade do solo ao longo do dia permitiu uma absorção maior de água e nutrientes pelas plantas enquanto, por outro lado, no solo descoberto ocorreu maior variação da umidade do solo ao longo do dia, em virtude da maior evaporação justificando, então, as diferenças observadas entre os tratamentos com mulching em relação ao solo descoberto. Dantas et al. (2011) observaram, estudando a produção e a qualidade do meloeiro cultivado com mulching plásticos, que a utilização dos mulching plásticos proporcionou um aumento expressivo na produtividade; entretanto, Medeiros et al. (2007) obtiveram, estudando a produção de melão influenciado por diferentes coberturas do solo, resultados semelhantes aos obtidos neste trabalho não observando, porém, diferença entre as cores de mulching e os menores valores em solos descobertos. Outro fator passível de ter contribuído para a obtenção desses resultados, foi a maior incidência de plantas daninhas ocorridas no solo descoberto acarretando, daí, maior competição por água, luminosidade e nutrientes com a cultura. Do mesmo modo, Morais et al. (2008) observaram, estudando a produtividade do meloeiro influenciado pela cobertura de solo, que a produtividade de frutos comercializáveis e total para o solo coberto com plástico foi superior à do solo descoberto e não houve diferença significativa para a produtividade de frutos comercializáveis em solo coberto com as diferentes cores de plástico.

Considerando o agrotêxtil observou-se efeito significativo para a massa média de frutos, produtividade comercial e total e produtividade não comercial (Tabela 3). Para a massa média de frutos os maiores valores foram obtidos nos tratamentos com agrotêxtil de 1 e $3^{\circ}$ cultivos e sem agrotêxtil (apenas com mulching) obtendo-se uma média de $3,54 \mathrm{~kg}_{\text {fruto }}{ }^{-1}$, superior em $27 \%$ em comparação com a testemunha. A diferença verificada no tratamento sem agrotêxtil e a testemunha se deve, sem dúvida, ao conjunto de fatores envolvendo a umidade do solo e a incidência de plantas daninhas visto que na testemunha não havia proteção de plantas com o agrotêxtil nem cobertura do solo.

Para PC e PT foram observados comportamentos semelhantes ao obtido para MMF, com menores valores na testemunha de forma que ocorreu, entre os tratamentos com agrotêxtil de $1^{\circ}$ e $3^{\circ}$ cultivos e sem agrotêxtil, uma produtividade média de 86,46 e $88,0 \mathrm{t} \mathrm{ha}^{-1}$ para PC e PT, respectivamente, correspondente a uma superioridade, em relação à testemunha, na ordem de $50 \%$ para PC e de $44,55 \%$ para PT (Tabela 3); a menor PNC ocorreu no tratamento sem agrotêxtil não diferindo do $1^{\circ}$ cultivo enquanto os maiores valores foram obtidos no agrotêxtil de $3^{\circ}$ cultivo e na testemunha.

Este comportamento ocorreu, provavelmente, em virtude da testemunha não ter recebido qualquer proteção contra as pragas (agrotêxtil) e controle de plantas daninhas (mulching), o que dificultou o crescimento das plantas de melancia uma vez que aumentou em muito a competição por água, luz e nutrientes e este efeito de competição permite perceber a diferença dos tratamentos com cobertura do solo e proteção de plantas em relação à testemunha. Segundo Freitas et al. (2009) dentre os fatores que interferem negativamente na qualidade da melancia, tal como em outras culturas, se destaca a interferência exercida pelas plantas daninhas, que competem com a cultura por água, luz e nutrientes, liberam substâncias alelopáticas, são hospedeiras de pragas e doenças, dificultam os tratos culturais e a colheita dos frutos e ainda podem prejudicar a qualidade do produto comercializável.

As plantas das parcelas que receberam o agrotêxtil se desenvolveram até os 21 dias após o transplantio, sem a infestação de pragas, principalmente da mosca minadora (Lirimyza spp), que se tornou a principal praga da cultura contribuindo para uma boa qualidade de área foliar e, em contrapartida, maior eficiência fotossintética uma vez que as 
plantas atacadas pela mosca minadora apresentam lesões em função das galerias que as moscas fazem nas folhas promovendo uma redução significativa da área fotossintética, o que pode causar secamento e queda prematura das folhas reduzindo, assim, a produção de fotoassimilados afetando a produtividade e a qualidade dos frutos. Jiménez et al.(2001) observaram, estudando o efeito do mulching plástico combinado com o agrotêxtil no controle da mosca branca, efeitos positivos quanto ao rendimento, à antecipação de colheita e ao controle praticamente total da incidência de pragas. Na cultura do melão Medeiros et al.(2007) verificaram que o uso do agrotêxtil proporcionou aumento significativo no número de frutos e na produtividade.

Para os parâmetros de qualidade de frutos não houve efeito significativo da cobertura do solo com mulching plástico e proteção das plantas com agrotêxtil (Tabela4).

Tabela 4. Valores médios para sólidos solúveis (SS), acidez titulável (AT), relação SS/AT de plantas de melancia, cv. Quetzale

\begin{tabular}{lccc}
\hline & \multicolumn{3}{c}{ Variáveis avaliadas } \\
\cline { 2 - 4 } & $\begin{array}{c}\text { SS } \\
\text { ('Brix) }\end{array}$ & $\begin{array}{c}\text { AT } \\
\text { (g ácido cítrico 100 } \mathbf{m L}^{-1} \text { de suco) } \\
\text { Mulching }\end{array}$ & SS/AT \\
Prata & $9,34 \mathrm{~A}$ & $0,675 \mathrm{~A}$ & $13,84 \mathrm{~A}$ \\
Branco & $9,72 \mathrm{~A}$ & $0,683 \mathrm{~A}$ & $14,23 \mathrm{~A}$ \\
Preto & $9,74 \mathrm{~A}$ & $0,717 \mathrm{~A}$ & $13,58 \mathrm{~A}$ \\
Testemunha & $9,27 \mathrm{~A}$ & $0,675 \mathrm{~A}$ & $13,73 \mathrm{~A}$ \\
\hline F & $1,84^{\mathrm{ns}}$ & $0,96^{\mathrm{ns}}$ & $0,31^{\mathrm{ns}}$ \\
CV (\%) & 3,80 & 5,88 & 7,80 \\
\hline & \multicolumn{3}{c}{} \\
$1^{0}$ Cultivo & $9,69 \mathrm{~A}$ & Agrotêxxtil & $0,717 \mathrm{~A}$ \\
$3^{0}$ Cultivo & $9,65 \mathrm{~A}$ & $0,667 \mathrm{~A}$ & $13,51 \mathrm{~A}$ \\
Sem agrotêxtil & $9,46 \mathrm{~A}$ & $0,692 \mathrm{~A}$ & $14,47 \mathrm{~A}$ \\
Testemunha & $9,27 \mathrm{~A}$ & $0,667 \mathrm{~A}$ & $13,67 \mathrm{~A}$ \\
\hline F & $1,38^{\mathrm{ns}}$ & $1,53^{\mathrm{ns}}$ & $13,89 \mathrm{~A}$ \\
CV (\%) & 3,44 & 5,17 & $0,74^{\mathrm{ns}}$ \\
\hline
\end{tabular}

Médias seguidas pela mesma letra maiúscula, na coluna, não diferem entre si pelo teste de Duncan a 0,05 de probabilidade; ns não significativo

Altos teores de SS em frutos de melancia são bastante desejáveis visto que este índice é um parâmetro muito importante na aceitação do produto pelo mercado consumidor.

Foram observados valores médios de $9,52^{\circ}$ Brix e $0,687 \mathrm{~g}$ ácido cítrico $100 \mathrm{~mL}^{-1}$ de suco para SS e AT, respectivamente. A relação sólidos solúveis/acidez titulável é uma das melhores formas de avaliação do sabor sendo mais representativa que a medição isolada de açúcares ou da acidez proporcionando boa ideia do equilíbrio entre esses dois componentes (Chitarra \& Chitarra, 2005).

\section{Conclusões}

1. A cobertura do solo com mulching plástico e a proteção das plantas com agrotêxtil proporcionaram maior rendimento de frutos de melancia.

2. A qualidade dos frutos não foi afetada pela cobertura do solo com mulching plástico e proteção das plantas com agrotêxtil.

3. O agrotêxtil poderá, se bem conservado, ser utilizado até três ciclos sem prejudicar a qualidade nem o rendimento da cultura.
4. Em locais em que haja uma grande pressão de pragas não seria possível produzir melancia sem a utilização do agrotêxtil; os tratamentos que não receberam proteção com o agrotêxtil e o mulching apresentaram produtividades inferiores.

\section{Agradecimentos}

Ao CNPq, pelo financiamento do projeto e bolsa de mestrado concedida à primeira autora.

\section{Literatura Citada}

ABINT - Associação Brasileira das Indústrias de Não Tecidos. Agrotêxtil: Uma nova alternativa de proteção para a agricultura. São Paulo: 2000.<http://www.abint.org.br/ manual-agrotextil-2.htm>. 15 Jun. de 2010.

Allen, R.G.; Pereira, L. S.; Raes, D.; Smith, M. Crop evapotranspiration: guidelines for computing crop water requirements. Rome: FAO,1998. 300p. Irrigation and Drainage Paper, 56.

Almeida, M. L. B.; Silva, G. G.; Rocha, R. H. C.; Morais, P. L. D.; Sarmento, J. D. A. R. Caracterização físico-química de melancia 'Quetzali' durante o desenvolvimento. Revista Caatinga, v.23, p.28-31, 2010.

Araújo, A.P.; Negreiros, M. Z.; Leitão, M. M. V. B. R.; Pedrosa, J. F.; Bezerra Neto, F.; Espínola Sobrinho, J.; Ferreira, R. L. F.; Nogueira, I. C. C. Rendimento de melão amarelo cultivado em diferentes tipos de cobertura do solo e métodos de plantio. Horticultura Brasileira, v.21, p.123-126, 2003.

Câmara, M. J. T.; Negreiros, M. Z. de ; Medeiros, J. F. de; Bezerra Neto, F.; Barros Júnior, A. P. Produção e qualidade de melão amarelo influenciado por coberturas do solo e lâminas de irrigação no período chuvoso. Ciência Rural, v.37, p.58-63, 2007.

Chitarra, M. I. F.; Chitarra, A. B. Pós-colheita de frutos e hortaliças: Fisiologia e manuseio. Lavras: ESAL/FAEPE, 2005. 785p.

Dantas, D. da. C.; Medeiros, J. F. de.; Freire, A. G. Produção e qualidade do meloeiro cultivado com filmes plásticos em respostas à lâmina de irrigação. Revista Ciência Agronômica, v.42, p.652-661, 2011.

Dantas, M. S. M. Rendimento e qualidade de frutos de melancia cultivada sob proteção agrotêxtil combinado com Mulching plástico. Mossoró: UFERSA, 2010, 50p. Dissertação Mestrado

EMBRAPA - Empresa Brasileira de Pesquisa Agropecuária. Sistema brasileiro de classificação de solos. Rio de Janeiro: Embrapa Solos, 1999. 412p.

Freitas, F. C. L.; Medeiros, V.F.L.P.; Grangeiro, L. C.; Silva, M.G.O.; Nascimento, P.G.M.L.; Nunes, G. H. S. Interferência de plantas daninhas na cultura do feijão-caupi. Planta Daninha, v.27, p.241-247, 2009.

Horton, R.; Bristow, K. L.; Kluitenberg, G. J.; Sauer, T. J. Crop residue effects on surface radiation and energy balance. Review. Theoretical and Applied Climatology, v.54, p.2737, 1996.

Huang, Y. L.; Chen, L. D.; Fu, B. J.; Huang, Z.L.; Gong, J. The wheat yields and water-use efficiency in the Loess Plateau: straw mulch and irrigation effects. Agricultural Water Management, v.72, p.209-222, 2005. 
IBGE - Instituto Brasileiro de Geografia e Estatística. http:// www.ibge.gov.br/servidor_arquivos_est. 26 Jan. 2011.

Jiménez, L. I.; Castillo, F. H.; López, J.M.; Ruvalcaba, B. C. Cubiertas flotantes, acolchado plastic y control de mosca blanca en el cultivo de calabacita. Revista Chapingo Serie Horticultura, v.7, p.159-169, 2001.

Jiménez, L. I.; González; A. Z.; López; J. M.; Martín, M. A. R. Q.; Ibarra; M. de la. R. Photosynthesis, soil temperature and yield of cucumber as affected by colored plastic mulch. Acta Agriculturae Scandinavica, Section B - Soil \& Plant Science. v.58, p.372-378, 2008.

Jiménez, L. I.; López, J. M.; Rio, A. J. L. del.; González, A. Z. Effect of plastic mulch and row covers on photosynthesis and yield and of watermelon. Australian Journal of Experimental Agriculture, v.45,p.1653-1657, 2005.

Jiménez, I. L.; Martín, M. R. Q.; Ibarra, M. de la. R.The effect of plastic mulch and row covers on the growth and physiology of cucumber. Australian Journal of Experimental Agriculture, v.44, p.91-94, 2004.

Liu, C. A.; Jin, S. L.; Zhou, L. M.; Jia, Y.; Li, F. M.; Xiong, Y. C.; Li, X. G. Effects of plastic film mulch and tillage on maize productivity and soil parameters. European Journal of Agronomy, v.31, p.241-249, 2009.

Medeiros, J. F. de; Santos, S. C. L.; Câmara, M. J. T; Negreiros, M. Z. Produção de melão Cantaloupe influenciado por coberturas do solo, agrotêxtil e lâminas de irrigação. Horticultura Brasileira, v.25, p.538-543, 2007.

Medeiros, J. F de.; Silva, M. C. C.; Câmara Neto, F. G.; Almeida, A. H. B de.; Souza, J de O.; Negreiros, M. Z de ; Soares, S. P. F. Crescimento e produção do melão cultivado sob cobertura de solo e diferentes freqüências de irrigação. Revista Brasileira de Engenharia Agrícola e Ambiental,v.10, p.792-797, 2006.

Miranda, N. O.; Medeiros, J. F. de; Nascimento, I. B.; Alves, L. P. Produtividade e qualidade de frutos de melão em resposta à cobertura do solo com plástico preto e ao preparo do solo. Horticultura Brasileira, v.21, p.490-493, 2003.
Morais, E. R. C.; Maia, C. E.; Negreiros, M. Z. de ; Araujo Junior, B. B ; Medeiros, J. F. de. Crescimento e produtividade do meloeiro goldex influenciado pela cobertura do solo. Scientia Agraria, v.9, p.129-137, 2008.

Moreno, S. F.M.; Ibarra, M. A. I.; Martínez, R.M.; Cohen, I. S.; Valencia, E. A. C.; Castorena, M. V. Respuesta de lasandía al acolchado plástico, fertilización, siembradirecta y transplante. Revista Fitotecnia Mexicana, v.28, p.351$357,2005$.

Negreiros, M. Z.; Costa, F. A.; Medeiros, J. F.; Leitão, V. B. R. M. M.; Bezerra Neto, F.; Espínola Sobrinho, J. Rendimento e qualidade do melão sob lâminas de irrigação e cobertura do solo com filmes de polietileno de diferentes cores. Horticultura Brasileira, v.23, p.773-779, 2005.

Ramakrishna, A.; Hoang, M.T.; Suhas, W.; Dinh, T.D. Effect of mulch on soil temperature, moisture, weed infestation and yield of groundnut in northern Vietnam. Field Crops Research, v.95, p.115-125, 2006.

Silva, F. C. Manual de análises químicas de solos, plantas e fertilizantes. Brasilia: Embrapa Informação Tecnologica, 2009, 627p.

Silva, M. C. C. Crescimento, produtividade e qualidade de frutos do meloeiro sob diferentes níveis de salinidade da água de irrigação e cobertura do solo. Mossoró: ESAM, 2002. Dissertação Mestrado

Silva, M. C. C.; Medeiros, J. F.de; Negreiros, M. Z.; Sousa, V. F. Produtividade de frutos do meloeiro sob diferentes níveis de salinidade da água de irrigação, com e sem cobertura do solo. Horticultura Brasileira, v.23, p.202-205, 2005.

Streck, N. A.; Schneider, P. M.; Buriol, G. A. Modificações físicas causadas pelo mulching. Revista Brasileira de Agrometeorologia, v.2, p. 131-42,1994.

Zhang, S. L.; Lo“vdahl, L.; Grip, H.; Tong, Y. A.; Yang, X. Y.; Wang, Q. J. Effects of mulching and catch cropping on soil temperature, soil moisture and wheat yield on the Loess Plateau of China. Soil and Tillage Research 102, p.78-86, 2009. 